\title{
A EMPRESA ESTRATEGISTA: A REVITALIZAÇÃO DA ÉTICA NAS RELAÇÕES EMPRESARIAIS E OS CÓDIGOS DE CONDUTA
}

\author{
THE STRATEGIST COMPANY: THE REVITALIZATION \\ OF ETHICS IN BUSINESS RELATIONS AND CODES OF CONDUCT
}

Frederico Thales de Araújo MARTOS ${ }^{1}$

Marina Bonissato FRATTARI ${ }^{2}$

\footnotetext{
${ }^{1}$ Doutor em Direito pela Faculdade Autônoma de Direito - FADISP (2014). Mestre em Direito pela FADISP (2012). Bacharel em Direito pela Faculdade de Direito de Franca (2009). Professor Titular de Direito Civil na Graduação da Faculdade de Direito de Franca - FDF (2016) atuando, também, como Professor - Convidado no Curso de Pós-Graduação desta Instituição. Professor efetivo de Direito Civil na Universidade do Estado de Minas Gerais, unidade de Frutal - UEMG/Frutal (2018). Integrante da comissão responsável pela elaboração de itens do BNI-ENADE 2015/2018 do INEP. Integrante do corpo permanente de avaliadores de curso de direito do INEP. Palestrante em diversas Instituições de Ensino. Advogado inscrito na OAB/SP. Associado ao IBDFAM - Instituto Brasileiro de Direito de Familía, ao Conselho Nacional de Pesquisa e Pós-Graduação em Direito CONPEDI e à Sociedade Brasileira para o Progresso da Ciência - SBPC. Autor de diversos artigos e livros acadêmicos. Desenvolve pesquisa científica. Contato: fredmartos@gmail.com. http://lattes.cnpq.br/422990855890554.

${ }^{2}$ Graduanda (2015-2019) pela Universidade do Estado de Minas Gerais, unidade Frutal. Atualmente é bolsista de ensino pelo programa PAPq, atuando como membro voluntária em outros projetos de pesquisa e extensão realizados na UEMG Frutal. Publicou artigos no campo do Direito, com maior foco em Direito Privado. Atualmente é estagiária no Tribunal de Justiça de Minas Gerais, com atuação na área criminal e de infância e juventude (2018-2019). Também, atuou como estagiária no setor jurídico e administrativo da Câmara Municipal de Frutal (2017-2018) e no escritório Advocacia do Trabalhador (2015-2017). Entre 2009 e 2012 atuou na instituição filantrópica Interact Club da cidade de Iturama/MG, chegando ao cargo de Vice-Presidente na gestão 2010/2011; atuou em projetos filantrópicos na escola Sistema Inteligente de Ensino e Aprendizado, Colégio Objetivo Iturama/MG de 2011 a 2013. Contato: marina.b.frattari@ hotmail.com. http://lattes.cnpq.br/8160577624852379.
} 
ISSUE DOI: $10.21207 / 1983.4225 .721$

\title{
RESUMO
}

Pretende-se, com a presente investigação científica, abordar as questões acerca do perfil da empresa contemporânea, verificando sua importância na sociedade atual e os reflexos de sua atividade no meio em que se encontra inserida. Com a mesma pretensão, será analisada e contextualizado os novos desafios encarados pela empresa no atual mercado concorrencial. Para alcançar o desiderato proposto serão avaliados os pontos relevantes da adoção de um planejamento socialmente responsável por parte das empresas, balizado pela ética e, por conseguinte, os pontos favoráveis de se assumir um papel mais consciente perante a sociedade. A revitalização da ética nas relações empresariais e a elaborações de Códigos de Conduta surgem como temáticas originadas da maturação da Responsabilidade Social da Empresa, motivo pelo qual merecem um tópico individualizado, apresentando as particularidades e a devida relação com a investigação científica realizada.

Palavras-chave: Ética empresarial, Gestão Empresarial, Códigos de Conduta.

\begin{abstract}
It is intended, with the present scientific investigation, to approach the questions about the profile of the contemporary company, verifying its importance in the present society and the reflexes of its activity in the environment in which it is inserted. With the same intention, the new challenges faced by the company in the current competitive market will be analyzed and contextualized. In order to achieve the proposed goal, the relevant points of the adoption of a socially responsible planning by the companies, based on ethics and, consequently, the favorable points of assuming a more conscious role in the society will be evaluated. The revitalization of ethics in business relations and the elaboration of Codes of Conduct emerge as themes originated from the maturation of Corporate Social Responsibility, which is why they deserve an individualized topic, presenting the particularities and the proper relationship with the scientific research carried out.
\end{abstract}

Keywords: Business Ethics, Business Management, Codes of Conduct

INTRODUÇÃO

A empresa hodierna apresenta não somente mudanças quantitativas como também qualitativas, em decorrência dos novos preceitos políticos, econômicos e sociais. A atividade empresarial passou por inúmeras e profundas transformações que lhe obrigou a mudar sua aparência e seu modo de ação, haja visto que a empresa, que antes tinha aspectos familiares e de reflexo local, hoje convive com as grandes multinacionais, de atuações transnacionais e que afetam a economia global.

Pretende-se, com a presente investigação científica, abordar as questões acerca do perfil da empresa contemporânea, verificando sua importância na sociedade atual e os reflexos de sua atividade no meio em que 
se encontra inserida. Com a mesma pretensão, serão analisados e contextualizados os novos desafios encarados pela empresa no atual mercado concorrencial.

A condução desta investigação científica demonstrará que a concepção na qual a atividade empresarial está voltada unicamente para os lucros mostra-se completamente obsoleta, pois a sociedade contemporânea engloba outros fatores mais condizentes com o Estado Democrático de Direito.

O novo perfil empresarial que surge interligado com a dimensão social reflete uma nova exigência mercadológica, pois se origina do anseio da sociedade para tal implementação. Assim sendo, mostra-se necessária realizar uma análise da empresa e sua importância no contexto socioeconômico.

A presente investigação científica visa a conscientizar o empresário de que a atividade desenvolvida por sua empresa interage com o ambiente ao qual está inserida, criando reciprocidade de dependência entre todos os agentes envolvidos.

Para alcançar o desiderato proposto, serão avaliados os pontos relevantes da adoção de um planejamento socialmente responsável por parte das empresas, balizado pela ética e, por conseguinte, os pontos favoráveis de se assumir um papel mais consciente perante a sociedade.

A revitalização da ética nas relações empresariais e as elaborações de Códigos de Conduta surgem como temáticas originadas da maturação da Responsabilidade Social da Empresa, motivo pelo qual merecem um tópico individualizado, apresentando as particularidades e a devida relação com a investigação científica realizada.

Pretende-se chegar à compreensão do grande valor da empresa que assume suas obrigações sociais e para isso será utilizado uma metodologia complexa, com a combinação de vários processos e técnicas de investigação e demonstração, caracterizando-se como um método híbrido com o uso das técnicas de análise e síntese, indução e dedução e dogmático do tema.

\section{A IMPERATIVIDADE DA ÉTICA NAS RELAÇÕES EMPRESARIAIS}


As empresas, por um longo período, organizaram-se de forma desumana, originando uma crise de ética sem precedentes históricos. Contudo, as sociedades estão resgatando os valores que, outrora cultivados, dignificavam o homem em busca do estabelecimento da ordem socioeconômica.

Na concepção atual, as empresas devem "assumir posições como agentes transformadores da sociedade, assumindo papéis para coibir ações que possam prejudicar seu público, seus clientes, seus fornecedores e a sociedade em que está estabelecida" (MENJIVAR, 2008, p. 208).

Em tempos de globalização e de internacionalização do mercado concorrencial, soa de forma paradoxal estabelecer critérios de ética negocial ou de boa-fé contratual nas relações empresariais. Todavia, isso ocorre, como afirma Santos (2000, pp. 23-25), pelo fracasso no cumprimento das promessas da modernidade e pela magnitude dos transtornos sociais causados por tais relações.

As transformações na atividade empresarial são reflexo de sua adequação ao processo morfológico pelo qual a sociedade passa. Assim sendo, a realidade social corrobora na fomentação de diversas teorias no campo empresarial que, até o presente momento, tinham uma significação periférica e de menor relevância (UGUINA, 2002, p. 192).

A Carta Encíclica Centesimus Annus trata dos novos valores almejados pela sociedade contemporânea, ressaltando a importância da empresa contemporânea na doutrina social da Igreja, que assim diz:

\begin{abstract}
A moderna economia de empresa comporta aspectos positivos, cuja raiz é a liberdade da pessoa, que se exprime no campo econômico e em muitos outros campos. A economia, de fato, é apenas um setor da multiforme atividade humana, e, nela, como em qualquer outro campo, vale o direito à liberdade, da mesma forma que o dever de usar responsavelmente. Mas é importante notar a existência de diferenças específicas da sociedade atual, e as do passado, mesmo se recente. Se outrora o fator decisivo da produção era a terra e mais tarde o capital, visto como um conjunto de maquinaria e de bens instrumentais, hoje o fator decisivo é cada vez mais o próprio homem, isto é, sua capacidade de conhecimento que se revela no saber científico, sua capacidade de organização solidária, sua capacidade de intuir e satisfazer a necessidade do outro (PAULO II, 1991, p. 46).
\end{abstract}

Nas lições de Berten (2011, p. 101), verifica-se que as análises de Weber visam a destacar a especificidade da ética econômica da religião ocidental. Nesse sentido, o jurista esclarece que, 
[...] ao se interrogar sobre a racionalização que caracteriza o desenvolvimento do capitalismo moderno, Weber observa que devemos compreender esse processo não como uma exacerbação da sede de lucro (que poderia ser encontrada em todas as épocas históricas e em todas as classes sociais) mas antes como a moderação desta sede e sua inscrição em uma empresa racional e metodicamente regrada. Portanto, o espírito do capitalismo - ao menos em sua origem - dá provas de certa 'ética'.

Ética ${ }^{3}$ e $\mathrm{Moral}^{4}$, por sua própria etimologia, denotam uma conduta ou comportamento que deve ser adotado nas relações em sociedade. Entretanto, não é possível indicar um conceito único para ética, pois ela varia conforme o contexto em que está aplicada.

Os paradigmas éticos são identificados por meio da avaliação subjetiva atribuída a certos elementos, norteados por meio da análise de valores, coerência e eficácia operacional. Assim sendo, tem-se a ética do dever, da lei, da liberdade, da felicidade, dos valores, do sujeito, da pessoa, da existência, da consciência, da situação, da ordem social. Em suma, tais paradigmas visam a simplificar a prática, desencadeando normas e modelos de comportamento com teor coerente e relacionado à história e cultura da sociedade (JOSAPHAT; DORTHE, 2012, p. 23).

Acerca das nuances enfrentadas pela adoção de um comportamento ético, Silva (1998, p. 23) assevera que:

\begin{abstract}
A extraordinária dificuldade que a Ética tem que superar é o reconhecimento das mediações que se interpõem entre o Bem absoluto e as ações particulares e contingentes. Nesta mediação, está contido o discernimento, que é a distinção entre o bem e o mal sem qualquer regra teórica de identificação. Pois as ações humanas acontecem sempre numa confluência complexa de circunstâncias, no meio das quais é preciso discernir o modo correto de agir.
\end{abstract}

Assim sendo, considerando que a atividade empresarial é fruto das mais diversas relações entre indivíduos, a ética também deve se fazer presente nas relações empresariais. Nesse sentido, adota-se a expressão "Ética Empresarial" na referência ao conjunto de preceitos éticos e de Responsabilidade Social que precisam ser observados nos negócios dos quais a empresa faz parte.

\footnotetext{
${ }^{3}$ A palavra vem do grego ethikos (ethos significa hábito ou costume). Na acepção empregada por Aristóteles, o termo refere-se a natureza ou o caráter do indivíduo.

${ }^{4}$ Moral deriva do latim mores, "relativo aos costumes". Seria importante atentar, ainda, para a etimologia da palavra "moral", que se originou a partir do intento dos romanos em traduzir a palavra grega êthica.
} 
Barbieri e Cajazeira (2012, p. 93) explicam que, enquanto a ética normativa trata de questões gerais, a Ética Empresarial ou dos Negócios é especificamente voltada para dar respostas aos problemas de natureza no âmbito das empresas.

A Ética Empresarial almejada reporta a valores morais específicos. Assim sendo, os valores morais refletem as crenças pessoais sobre os comportamentos éticos postulados. Logo, a ética e os valores morais se complementam.

Para Wiley (2013):

A ética pode ser definida de várias maneiras. Afirma-se que ética é justiça. Em outras palavras, inclui princípios que todas as pessoas racionais escolheriam para reger o comportamento social, sabendo que eles podem ser aplicados também a si mesmas. Por meio do estudo da ética, as pessoas entendem e são dirigidas pelo que for moralmente certo ou errado. Entretanto, o assunto continua controvertido. Afinal, aquilo que é eticamente correto para uma pessoa pode ser errado para outra.

A Ética dos Negócios se apresenta como um compromisso entre a moral e o interesse. Assim sendo, defende-se a presença da moral em todas as relações, inclusive na concorrência. Todavia, em contraponto, sempre será necessário avaliar o interesse (ethics pays) das partes, pois os homens são incapazes de se determinarem nos seus atos, a partir apenas da percepção do bem e do mal (JOSAPHAT; DORTHE, 2012, pp. 38-39).

Segundo Velasquez (2000, p. 15), a Ética Empresarial preocupase com as normas morais na medida em que elas se relacionam com as práticas empresariais. Logo, trata-se do estudo das normas morais e sua aplicação às empresas e seus stakeholders.

Quanto à diferenciação de ética e moral, Ashley (2005, p. 05) explica que a ética é mais sistematizada e corresponde a uma teoria de ação estabelecida rigidamente. A moral, em contrapartida, é concebida menos rigidamente, possibilitando variações em conformidade com o País, o grupo social, a organização ou mesmo o indivíduo em questão.

O processo de ética deve ser praticado de forma endógena nas práticas empresariais, iniciando-se pelos controladores, passando pelos empregados e fornecedores, até alcançar as relações com os consumidores. 
Destarte, considerando que a atividade empresarial decorre do interesse de seus agentes, esses devem ser considerados depositários primários dos encargos éticos, uma vez que a atuação da empresa reflete as decisões e ações de seus responsáveis.

Todavia, em uma perspectiva secundária, a empresa surge como responsável pelas obrigações e deveres éticos de sua atividade, pois suas obrigações em relação aos seus atos devem-se ao fato de que alguém, em seu nome e com poderes para tanto, pratica tais atos.

Assim sendo, o agente não pode utilizar a empresa como escudo para praticar atos antiéticos, pois a atividade empresarial reflete seu interesse. Da mesma maneira, a empresa não representa um ente imune à responsabilização, pois os atos empresariais são praticados pelos agentes dentro de suas atribuições, representando os interessas da empresa.

A ética relaciona-se à adoção de valores e critérios condutores da busca pelo bem comum. Assim sendo, ética fundamenta a Responsabilidade Social na medida em que os princípios da ordem moral, filosófica e religiosa são indicadores da modificação do comportamento empresarial de forma a açambarcar, em sua gestão, um veio voltado para assuntos não diretamente ligados ao seu objetivo social (HUSNI, 2007, p. 93).

A Ética Empresarial consolida-se em um cenário de globalização econômica. Neste contexto, as empresas, preocupadas em se tornar marcas multinacionais e sem fronteiras, devem se preocupar com as questões culturais dos povos em que sua atividade está inserida.

Não integra o escopo da presente pesquisa a análise das causas que levam à globalização; contudo, assinala-se a importância de se criar uma nova maneira de pensar a respeito do comportamento moral das pessoas e organizações frente a essa nova realidade.

No campo das postulações éticas, o filósofo Singer (2004) afirma a necessidade da sociedade em compreender que os efeitos da globalização colocaram em evidência que "todos vivem em um só mundo" que está inteiramente interligado. Assim sendo, a consolidação de uma postura acobertada pela ética é vital para criar a devida harmonização entre as nações, com a consequente preservação da soberania dos Estados ${ }^{5}$, afastando a possibilidade de eventuais conflitos entre os povos.

\footnotetext{
${ }^{5} \mathrm{O}$ conceito de soberania, entretanto, sempre causou polêmica devido à falta de unanimidade em definilo e à disparidade que parece sempre ter existido entre o conceito teórico e aquilo que pode suceder no
} 
Sobre os efeitos da globalização e a necessidade da consolidação de posturas éticas como corolário de preservação da sociedade mundial, Singer (2004, p. 13) entende que o comportamento moral deve ser em conformidade com o grupo em que se encontra inserido, seja uma tribo ou uma nação. Assim sendo, como consequência da globalização, a postura moral deve se justificar perante o mundo inteiro. Tal necessidade cria a base material para uma nova ética que atenda aos interesses de todos os habitantes do planeta, algo que, apesar de muito retórico, nenhuma ética precedente conseguiu.

Como resultado da globalização, é possível verificar duas tendências: a de homogeneização das culturas entre os povos e, na corrente inversa, a solidificação de suas diferenças (crenças), da qual o choque entre culturas com percepções divergentes resulta na impossibilidade de comunicação entre suas ideologias.

Assim sendo, para a atuação empresarial neste cenário globalizado que surge, verifica-se a necessidade de se desenvolver uma nova ética universal, consoante as pretensões apresentadas no relatório "Nossa Diversidade Criadora", de autoria da Comissão Mundial da Cultura e Desenvolvimento, promovida pela $\mathrm{UNESCO}^{6}$.

A Responsabilidade Social atrela-se às expectativas da globalização e o reconhecimento de uma empresa como possuidora de um trabalho ético mostra-se vital para sua continuidade. Todavia, caso a ação social esteja voltada somente para a divulgação, e não fizer parte de sua filosofia, o elo com o consumidor será quebrado, por não se tratar de um trabalho autêntico e comprometido (NEVES, 2001, p. 107).

Destarte, em busca pela compatibilização das ideologias diversas existentes, verifica-se a adoção, por parte das empresas, de padrões éticos e morais com tendências mais rigorosas.

As lições de González (2011) são precisas ao destacar a importância vital de que a empresa adote um plano estratégico relacionado à Ética Empresarial. Nesse sentido, o autor destaca o sucesso no mercado

\footnotetext{
mundo fático. Essa disparidade parece aumentar a cada dia, diante da nova realidade que se apresenta: a realidade do mundo global.

${ }^{6}$ De acordo com o relatório "Nossa Diversidade Criadora", as principais fontes de ideias norteadoras na nova ética universal alinham-se com os preceitos de Direitos Humanos; Fortalecimento da Democracia e dos Componentes da Sociedade Civil; Proteção das Minorias; Compromisso com as soluções pacíficas das controvérsias e negociações equitativas; Equidade em cada geração e entre gerações (UNESCO, 1997, pp. 47-63).
} 
econômico de determinadas empresas que incorporaram a figura do deontólogo no seu quadro estratégico e funcional.

Nesse sentido, González (2011) afirma que:

\begin{abstract}
De uns tempos para cá, e em especial após o debate da Enron e o início de um ciclo de vacas magras para a economia mundial, vários participantes de organizações empresariais voltaram os olhos para a França. Ali, há mais de 5 anos, pratica-se a Deontologia, um segmento da Filosofia que estuda os princípios, os fundamentos e os sistemas de moral. Já são mais de 800 empresas que possuem um deontologista, uma exigência do Conselho do Mercado Financeiro local. O deontologista é o guardião da Ética mercantil. É ele que analisa todo possível conflito de interesse e previne a empresa da tomada de qualquer decisão considerada antiética. A PriceWaterhouseCoopers - PWC francesa, por exemplo, é um exemplo para todas as demais no Mundo, pois além de possuir um deontologista no escritório, já desenvolveu uma cultura corporativa que estabelece ser a prática da deontologia nas empresas que atende como primordial para o sucesso empresarial. [...] A Deontologia está se tornando um elemento fundamental da gestão para o sucesso das empresas numa nova etapa do desenvolvimento capitalista. Sem dúvida, esta é uma das formas de se implementar práticas de controle e segurança de gestão, focadas na ética.
\end{abstract}

No atual viés ao qual se encaixa a atividade empresarial, constata-se que o sucesso das práticas negociais no mercado globalizado está no compartilhamento das mesmas perspectivas entre a sociedade e a empresa, ou seja, investir na sociedade mostra-se mais efetivo do que fazer mera caridade.

Num mundo globalizado, em que a competição pode resvalar para a concorrência desleal, em que a capacidade de ação da Cidadania ganha dimensão inédita, adotar um posicionamento responsável tem muito a ver com a sobrevivência das empresas, mas também com a dignidade pessoal de quem a conduz e daqueles com quem a corporação possui relações (PONCHIROLLI, 2012, p. 42).

Em uma análise pragmática da Ética Empresarial, Adeotado (2002, pp. 139-140) explica que as normas éticas preenchem a mesma função vital: reduzem a imensa complexidade das relações humanas e ajudam o ser humano a decidir sobre como agir. É a decisão que neutraliza o conflito.

Os indicadores das pesquisas realizadas pelo Instituto Ethos (OECD, 2012) demonstram que a atuação baseada em princípios éticos elevados e a busca de qualidade nas relações são manifestações da Responsabilidade Social Empresarial. Na atualidade, a transparência nas relações 
comerciais representa fator de legitimidade social e um importante atributo positivo para a imagem pública e a reputação das empresas.

Nessa esteira, a adoção de padrões de conduta ética que valorizem o ser humano, a sociedade e o meio ambiente surgem como necessidade primordial à continuidade da empresa no mercado, pois a implantação de relações de qualidade constroe-se a partir de valores e condutas capazes de satisfazer necessidades e interesses dos parceiros, gerando valor para todos.

Todavia, algumas empresas relutam em estabelecer condutas antiéticas e implantam o bait-and-switch7 em seus negócios. Entretanto, em decorrência da velocidade com que as notícias são transmitidas aos consumidores, principalmente pela internet, esse tipo de atividade empresarial está fadado ao fracasso. Curiosamente, websites como o "youtube.com" e "reclameaqui.com.br" estão se mostrando ferramentas eficazes para que os consumidores alertem a sociedade a respeito de comportamento reprováveis adotados por algumas empresas.

Vale ressalvar que, para a sustentação de altos padrões de comportamento empresarial, a empresa não deve se preocupar unicamente em identificar os agentes de negócios antiéticos, pois, muito embora tal preocupação seja necessária, não assegura uma conduta ética nos negócios.

Para a consolidação de uma conduta ética, espera-se que a empresa não se concentre unicamente no que não deve ser feito, mas também se organize sobre práticas fundamentadas no comportamento ético e econômico a serem adotados.

O perfil da sociedade contemporânea exige que as empresas adotem a ética em suas relações. Deve prevalecer a filosofia de que o lucro somente é ético se respeitados os preceitos da ordem social que se estabelecem pela plena satisfação pessoal dos empregados e consumidores, pelo pagamento correto de salários e tributos, pelo estabelecimento de políticas

\footnotetext{
7 A bait-and-switch é uma conhecida estratégia de organizações antiéticas, que consiste em ofertar, pelos meios de comunicação, um produto com preço reduzido ("isca"), que na verdade nunca é disponibilizado ao consumidor, sob a conhecida argumentação de que o 'estoque está esgotado devido à grande procura'. Assim agindo, exercem uma poderosa influência sobre o consumidor, atraindo-o para a sua empresa, com o objetivo de lhe vender um produto de valor mais significativo, que lhe proporcione maior margem de lucro.
} 
de desenvolvimento sustentável e inclusão social e demais assuntos correlatos $^{8}$.

Assim sendo, a ética empresarial está relacionada em assumir uma postura socialmente responsável por parte das empresas, ou seja, tratase do compromisso de adotar um desenvolvimento sustentável, reconhecendo a importância de seus empregados, suas famílias, a comunidade local e a sociedade como um todo visando à melhoria da qualidade de vida de todos (WANDERLEY; COLLIER, 2000, p. 45)

Uguina (2002, pp. 206-207) destaca que "a empresa quer apresentar-se como uma comunidade humanizada onde o trabalhador possa integrar-se e encontrar a afetividade e o protagonismo que a sociedade não lhe confere".

Assim sendo, é inevitável a ocorrência de eventuais conflitos entre a busca pela lucratividade e o desenvolvimento da atividade empresarial pautada nos preceitos éticos e de Responsabilidade Social. Todavia, em tais casos deve-se buscar no compromisso criador a resolução do confronto.

Assim sendo, a Ética Empresarial mostra-se ligada, intrinsecamente, à postura socialmente responsável adotada pelas empresas por meio de 3 (três) perspectivas: seja pelo respeito à moral, seja pela postura competitiva do mercado, ou por ambas. Em verdade, reitera-se que a vitaliciedade de uma empresa no mercado atual é corroborada pela adoção de planos estratégicos apoiados na ética.

\section{A IMPLANTAÇÃO DE CÓDIGOS DE CONDUTA PELAS EMPRESAS}

Os Códigos de Ética estruturam e sistematizam as exigências éticas de todos os profissionais no tríplice plano: de orientação, de disciplina e de fiscalização. Assim sendo, Códigos de Ética integram o sistema de valores que orienta a conduta de determinados grupos (PONCHIROLLI, 2012, p. 39).

O Código de Ética da Empresa representa uma importante ferramenta que demonstra seu compromisso em estabelecer um comportamento

\footnotetext{
${ }^{8}$ Também deve ser considerado o comportamento, de contratação de deficientes, a luta contra a discriminação, a integração dos trabalhados imigrantes, o favorecimento de universidades e centros de investigação, etc.
} 
alinhado à moralidade. Nesse diapasão, depreende-se que os valores morais de um grupo ou organização definem o que é ser ético para si e, a partir daí, elaboram-se rígidos códigos éticos que precisam ser seguidos, sob pena de ferirem os valores morais preestabelecidos (ASHLEY, 2005, p. $05)$.

Destarte, em que pese o Código de Ética Empresarial se justificar nos ideais, na missão e na visão da empresa, tais elementos não precisam ser, necessariamente, contemplados a rigor. Todavia, deve haver clareza, de um modo geral, no caráter regulamentador e punitivo de seus mandamentos.

Com efeito, o Código de Ética representa o instrumento que busca a efetivação dos princípios e da missão assumidos pela empresa. Sua função é orientar as ações de seus agentes e esclarecer sua postura social em face de seus stakeholders.

Ashley (2005, p. 18), destaca que:

A maioria das empresas que desejam afirmar a ética em seu comportamento moral elabora códigos de ética próprios. Tais códigos permitem que todos dentro e fora da organização conheçam o comportamento da alta gerência com a sua definição de padrão de comportamento ético e, mais importante, que todos saibam que os dirigentes esperam que os funcionários ajam de acordo com esse padrão. O código define o comportamento considerado ético pelos executivos da empresa e fornece, por escrito, um conjunto de diretrizes que todos os funcionários devem seguir.

É de significativa relevância que o conteúdo do Código de Ética seja o reflexo das práticas empresariais e condutas realizadas pelas pessoas relacionadas, inclusive pelo alto escalão da empresa, pois, para comprovar a efetividade de seus mandamentos, o comportamento de todos precisa estar em sintonia com tais diretrizes, principalmente dos que exercem cargos superiores.

Ashley (2005, p. 18) ensina que:

A alta gerência deve não somente explicar seu apoio a esse código como também demonstrar ostensivamente que opera com base nele, na prática de seu cotidiano e não apenas na intencionalidade de seu discurso. A atitude e o comportamento da alta gerência em relação ao Código de Ética da empresa dão o tom para a atitude e o comportamento dos funcionários a ela subordinados. Quando a alta gerência diz sustentar o código, mas faz exatamente o contrário do que ele reza, os funcionários dos demais níveis hierárquicos presumem que o código não é um documento sério. Por outro lado, se a alta gerência afirma que apoia o código e suas ações demonstram 
isso, os funcionários a ela subordinados passam a considerar o código um documento legitimado pela direção da empresa.

Moreira (2008, p. 68) ressalva que "a imposição de Códigos de Conduta Ética, por si só, não garante que as empresas sejam éticas; isso só se consegue se as pessoas que as compõem forem íntegras, isto é, possuidoras de todas as virtudes morais".

Para estabelecer os padrões éticos a serem adotados, devem-se analisar as peculiaridades de cada empresa, sua atuação no mercado, seu público e os reflexos de sua atividade em face de seus stakeholders. Da mesma forma, é preciso identificar quais são as pretensões da empresa e o que esperar de seus funcionários.

Husni (2007, p. 96) destaca que o Código de Ética deve ser criado de tal forma que reflita a missão da empresa, seus valores intrínsecos e extrínsecos, e o compromisso desta com os agentes internos e externos (stakeholders).

É importante mencionar que cada empresa possui características singulares e, desse modo, o Código de Conduta deve ser elaborado em conformidade com o perfil de cada uma, não sendo possível a adaptação de um padrão preestabelecido.

Nesse diapasão, citam-se os Códigos de Ética do Banco Itaú e do Grupo Pão de Açúcar, disponíveis em suas websites, como bons exemplos de códigos elaborados. Em que pese a recomendação de não utilizar o teor de tais códigos para outras empresas (em vista das evidentes incompatibilidades), nada impede que possam servir como referências, para uma nova codificação a ser criada.

Cumpre ressaltar que o Código de Ética precisa resultar do consenso entre as pessoas envolvidas, e que nele deve haver participantes de todas as classes relacionadas ao desenvolvimento da atividade empresarial. Logo, tal normativa não pode se originar da vontade e do envolvimento de um único sujeito.

Ainda sobre a elaboração do Código de Ética, deve-se observar que, para gerar amplo comprometimento, deve ser, preferencialmente, desenvolvido por um comitê representativo de todos os grupos e níveis funcionais e gerenciais. Esse comitê deve não apenas elaborar como também preparar o plano de implementação e atualização de todos os seus aspectos. Se necessário, a empresa pode contratar serviços externos de consultoria em comunicação e especialistas em ética, a fim de apoiar a elaboração de 
um plano viável para a implementação e a atualização do código (ASHLEY, 2005, p. 18).

Destarte, mostra-se imperioso o envolvimento de diversos sujeitos na elaboração do Código de Ética, pois sua eficácia e validade resultarão da aceitabilidade dos agentes relacionados à atividade empresarial. Quando o código é fruto de consenso entre as pessoas envolvidas, a vivência e as posturas éticas serão realidades visíveis na empresa (PONCHIROLLI, 2012, p. 40).

Husni (2007, p. 96) assevera que um documento desta natureza deve ser elaborado após minucioso estudo geral da atividade empresarial desenvolvida e da detecção de seus pontos de sensibilidade.

Ponchirolli (2012, p. 40) explica o seguinte:

A razão de ser do Código de Ética é fornecer critérios ou diretrizes para que as pessoas descubram formas éticas de se conduzir. É mais para orientar do que solucionar os dilemas éticos da organização. A maioria dos códigos aborda temas como: conflitos de interesse, conduta ilegal, segurança dos ativos da empresa, honestidade nas comunicações dos negócios da empresa, denúncias, suborno, entretenimento e viagem, propriedade de informação, contratos governamentais, responsabilidade de cada stakeholders, assédio moral, assédio sexual, uso de drogas e álcool.

O conteúdo do Código de Ética deverá ser formado por um conjunto de práticas e políticas específicas, e integram seu escopo regulamentar os campos identificados como mais vulneráveis no exercício da atividade empresarial.

Cumpre destacar que, quanto maior a amplitude de stakeholders relacionados às diretrizes adotadas, maior será a recepção de tais procedimentos empresariais junto à sociedade.

Para que o Código de Ética apresente um teor coeso e praticável, deverá ser fruto do diálogo e consenso entre a realidade e a disponibilidade de todos os grupos relacionados com a atividade empresarial. De nada adianta a elaboração de diretrizes e mandamentos a serem respeitados em um ambiente, se sua aplicabilidade mostra-se incompatível com os interesses de seus stakeholders.

Quanto ao conteúdo do Código de Ética, os tópicos a serem elaborados devem abordar, por exemplo, assuntos relacionados ao cumprimento da legislação, da proteção patrimonial, da resolução de litígios internos e externos, da transparência na comunicação, práticas ilegais e ilícitas, etc. 
No que diz respeito aos funcionários, devem-se abordar os procedimentos de contratação, desenvolvimento e crescimento profissional, lealdade, respeito, saúde, lazer, segurança, comportamento interno e externo, demissões, assédio, uso de entorpecentes, alcoolismo e demais assuntos correlatos.

É inegável o interesse da atividade empresarial em atingir lucros. Contudo, estes não podem ser alcançados em detrimento da exploração dos empregados e da inobservância da função social da empresa.

Assim sendo, a empresa moderna precisa adotar a política do diálogo nas relações com os seus stakeholders, demonstrando real e efetiva preocupação com todos. A existência de um diálogo franco e legal representa as prerrogativas do Direito e do bom senso.

Sua atuação deve alinhar-se com as políticas de valorização dos empregados e de preservação ao meio ambiente, pois assim alcançará o reconhecimento público e notório da sociedade, fixando-se no mercado e realizando sua função social e, por fim, conseguindo o tão almejado lucro.

Para obter maior efetividade, o Código de Ética precisa apresentar diretrizes sobre a postura adotada junto aos consumidores e à comunidade na solução de problemas, marketing e propagandas, qualidade no atendimento, acessibilidade de informações, dentre outros.

A empresa contemporânea deve desenvolver suas atividades voltadas aos anseios sociais, que estão inseridos no comportamento ético e socialmente responsável do empresário.

Integram, também, o escopo do Código de Ética: a relação com fornecedores, acionistas, empresas terceirizadas, sindicatos e órgãos públicos; condutas restritivas; participação da empresa na sociedade; e sanções e demais assuntos que se mostrem relevantes para a implantação da ética no exercício da atividade empresarial.

Um ponto significante que merece destaque diz respeito à previsão de sanções ${ }^{9}$, pois elas apresentam com clareza as práticas adotadas pela empresa. Em caso de desvio de conduta do qual caiba uma sanção, Husni

\footnotetext{
${ }^{9}$ Quanto às sanções, Husni (2007, pp. 96-97) destaca que: "Seria conveniente que um código de melhores práticas, de cunho ético e moral, também disciplinasse acerca das sanções àqueles que não cumprissem para com os seus termos. Neste ponto é importante mencionar que uma sanção de natureza externa, só faria sentido se atingisse o próprio negócio jurídico em andamento. [...] A outro lado, as sanções de âmbito interno podem ser melhor graduadas e mais efetivas coma criação de uma escala, que pode ir da simples advertência à suspensão ou despedida por justa causa com relação àqueles funcionários reincidentes na conduta".
} 
(2007, p. 99) destaca que o "Código de Ética poderá se refletir diretamente nas regras morais previstas no citado diploma, a legitimar os procedimentos legais que podem redundar na perda do cargo e na necessidade indenizatória".

Ashley (2005, p. 18) explica que:

A implementação de um Código de Ética envolve ainda a informação de que o código não deve ser violado, mas os executivos precisam ser cautelosos nas proibições. Não devem, por exemplo, fazer uma lista de condutas antiéticas, uma vez que não é viável relacionar todos os casos possíveis, e os funcionários poderiam pensar que tudo que não está na lista é considerado ético e legítimo. O Código de Ética deve ser afirmativo, ou seja, deve enfatizar as condutas que devem ser demonstradas em vez de destacar o que é reprovável.

Para a devida implementação do Código de Ética, é fundamental que se realize a publicidade de seu conteúdo pelos mais diversos meios de comunicação (murais, sites na internet, material de publicidade, etc.), pois deve alcançar a necessária aprovação, compreensão e apoio de todos os envolvidos.

O Código de Ética deve apresentar conteúdo de fácil assimilação, a compreensão de suas regras deve ser objetiva e clara, principalmente daquelas de maior importância e com maior apelo ético e moral.

Insta salientar que a implementação de um Código de Ética corrobora a possibilidade de fortalecer a integração e o comprometimento de todos os grupos que se envolvem com determinada empresa.

Ademais, a adoção de um Código de Ética permite a uniformização de critérios a serem adotados pela empresa, fornecendo maior respaldo às decisões a serem tomadas pelos seus agentes e expandindo o acesso à sua forma de atuação perante a sociedade.

É importante ressaltar, também, que o Código de Ética proporciona maior segurança aos trabalhadores que passam a conhecer as políticas e as ações da empresa, pois define com clareza sua missão, a possibilidade de crescimento profissional e a solução de problemas em caso de desvio de conduta.

Nesse diapasão, observa-se que, em consequência da adoção de Códigos de Ética, a empresa ingressa na seara de atuação de agente social e de desenvolvimento sustentável, pois assume uma visão para o futuro, como também sua postura e a de seus agentes com referência à diversidade de relações jurídicas que pratica diuturnamente (HUSNI, 2007, p. 93). 
Assim sendo, o Código de Ética proporciona maior harmonia à atividade empresarial, traz ordem, clareza, tranquilidade e adota referências a serem seguidas e respeitadas. Logo, a empresa assume sua missão e seu compromisso junto à sociedade, tornando-se referência e cumprindo com sua Responsabilidade Social.

As empresas preocupadas em adotar posturas éticas e que fazem uso de codificações de cunho moral, são comandadas por empresários conscientes de que sua atividade também é responsável pela edificação do futuro das sociedades.

A Ética Empresarial representa uma maior proximidade com os anseios dos consumidores e a adoção de um Código de Conduta condizente representa o principal meio pelo qual a empresa apresenta, de forma sólida, o seu compromisso ético com o desenvolvimento econômico e social.

\section{$5 \quad$ CONCLUSÃO}

O passado demonstrou que, por um longo período, as empresas se organizaram de maneira desumana, originando, em consequência, uma crise de ética sem precedentes históricos. Nesse cenário, as sociedades iniciaram um processo de resgate dos valores que, outrora cultivados, dignificavam o homem em busca do estabelecimento da ordem social e econômica.

Diante do exposto, a empresa deve ser compreendida além da figura do seu empresário, atingindo outros organismos que são diretamente influenciados (e influenciadores) por sua atuação. Logo, trata-se da conscientização dos reflexos decorrentes do exercício empresarial.

O cumprimento do domínio ético é fundamental para o exercício da Responsabilidade Social. A adoção de padrões de conduta ética que valorizem a relação de negócios surgiu como meio de sobrevivência e adequação da empresa ao mercado global.

Em busca da consolidação de um comportamento balizado na ética, surge o Código de Conduta como importante ferramenta normativa dentro do grupo empresarial. Para sua elaboração, consideram-se os valores morais definidos por seus agentes como preponderantes e fundamentais para orientar a conduta de determinados grupos. 
Assim sendo, a empresa contemporânea deve realizar seu planejamento demonstrando real compromisso com os anseios sociais existentes. Nesse diapasão, deve ser implantando um comportamento ético e socialmente responsável que demonstre sua adequação às perspectivas do meio em que se encontra inserida.

Os elementos formadores da empresa estão atrelados à realidade social e histórica da sociedade. Qualquer tentativa, no intuito de trazer um conceito prático, que deixa de considerar a realidade, mostra-se inócua.

As necessidades da sociedade obrigam as empresas a inserirem em suas marcas valores de ordem social, pois o consumidor da atualidade mostra-se preocupado e consciente com os preceitos da dignidade humana e do desenvolvimento sustentável.

Sabe-se que a empresa arca financeiramente com todo o planejamento para atuar no âmbito da responsabilidade social. Entretanto, o empresário que se mostra atuante nessa área consegue atrair mais consumidores, o que geralmente aumenta os lucros da empresa, compensando o investimento realizado.

Os Códigos de Conduta estruturam e sistematizam as exigências éticas de todos os profissionais no tríplice plano: de orientação, de disciplina e de fiscalização. Trata-se de um instrumento que busca a efetivação dos princípios e da missão assumidos pela empresa por meio da regulamentação do comportamento social em face de seus stakeholders.

As novas responsabilidades sociais assumidas pela empresa se confrontam com a gênese de sua expansão global, pois sua origem mostrase arraigada aos ideais do liberalismo. Todavia, para alcançar sua premissa maior, que ainda é o lucro, a adoção de um comportamento socialmente responsável é insofismável diante do mercado concorrencial e dos interesses da sociedade no plano atual.

\section{REFERÊNCIAS BIBLIOGRÁFICAS}

ADEOTADO. João Maurício. Ética e Retórica: Para uma Teoria da Dogmática Jurídica. São Paulo: Saraiva, 2002.

ASHLEY, Patrícia Almeida. Ética e Responsabilidade nos Negócios. 2a ed. Saraiva: São Paulo, 2005.

BARBIERI, José Carlos; CAJAZEIRA, Jorge Emanuel Reis. Responsabilidade Social Empresarial e Empresa Sustentável. $2^{\mathrm{a}}$ ed. São Paulo: Saraiva, 2012. 
BERTEN, André. Modernidade e Desencatamento - Nietzsche, Weber e Foucault. Trad.: Marcio Anatole de Sousa Romeiro. São Paulo: Saraiva, 2011.

HUSNI, Alexandre. Empresa Socialmente Responsável. São Paulo: Quartier Latim, 2007.

JOSAPHAT, Carlos; DORTHE, Jacques Pasquier. Sucesso nos Negócios e Realização Humana. Responsabilidade e Rentabilidade em Debate. Trad.: Marcio Anatole de Sousa Romeiro. São Paulo: Globus, 2012.

MENJIVAR, Débora Fernandes Pessoa Madeira. A Cláusula Geral da Função Social no Novo Código Civil e no Estatuto da Cidade. in: Revista Ciência Jurídica, v. 143, pp. 177-208, 2008.

MENEZES, Vitor Hugo Mota de. Poluição Transfronteiriça em Face da Soberania. Estudos de Direito Ambiental - Licenciamento, Reserva Natural Privada e Poluição Transfronteirica. Manaus: EDUA, 2007.

MOREIRA, José Manuel. As Contas com a Ética Empresarial. 2ª ed. Cascais: Principia, 2008.

NEVES, Márcia. Marketing Social no Brasil: A Nova Abordagem na Era da Gestão Empresarial Globalizada. Rio de Janeiro: e-papers, 2001.

OECD - Organization for Economic Co-operation and Development. Indicadores Ethos. Da responsabilidade Social Empresarial. Disponível em: http://www.oecd.org/dataoecd/56/11/1922148.pdf, Acesso em: 05.jan.2012.

PAULO II, João. Centesimus Annus - Carta Encíclica. São Paulo: Paulinas, 1991.

PONCHIROLLI, Osmar. Ética e Responsabilidade Social Empresarial. 5ª ed. Curitiba: Juruá, 2012.

SANTOS, Boaventura de Souza. A Crítica da Razão Indolente. Contra o Desperdício da Experiência. São Paulo: Cortez, 2000.

SILVA, Franklin Leopoldo. Da Ética Filosófica à Ética em Saúde. in: Iniciação à Bioética. COSTA, Oselka; GARRAFA, Volnei (Coords.). Brasília: Conselho Federal de Medicina, pp. 19-35, 1998.

SINGER, Peter. Um Só Mundo: A Ética da Globalização. São Paulo: Martins Fontes, 2004.

UGUINA, Jesús R. Mercader. Derecho del Trabajo, Nuevas Tecnologías y Sociedad de la Información. Valladolid: Lex Nova, 2002.

UNESCO/ Comissão Mundial de Cultura e Desenvolvimento. Nossa Diversidade Criadora. Brasília: Unesco Brasil e Papiros, 1997.

VELASQUEZ, Manuel G. Ética em los Negócios: Conceptos y Casos. México, DF: Prentice Hall, 2000.

WANDERLEY, Lilian S. Outtes; COLLIER, Jane. Responsabilidade Social das Empresas: Na Busca do Referencial Teórico. Rio de Janeiro: Revista Angrad., v. 1, nº 2, pp. 40-51, out./dez., 2000.

WILEY, Carolyn. O ABC da Ética. Disponível em: http://www.perspectivas.com.br/refle33.htm. Acesso em: 15.out.2013. 